\title{
In-situ $\mathrm{CH}_{4}-\mathrm{CO}_{2}$ Dispersion Measurements in Rock Cores
}

2

4 Department of Chemical Engineering, University of Western Australia, Crawley, WA, 5 Australia

6

$7 \quad *$ Corresponding author

8 Email: michael.johns@uwa.edu.au

9

10

11 Keywords:

12 enhanced gas recovery, core flooding, $\mathrm{CO}_{2}$, dispersion, MRI

13

14

15

16

17

18

19

20

21

22

23

24 
26 Injection of carbon dioxide $\left(\mathrm{CO}_{2}\right)$ into a natural gas reservoir is an emerging 27 technology for enhanced natural gas recovery (EGR) realizing increased natural gas 28 production whilst sequestering the injected $\mathrm{CO}_{2}$. However given that $\mathrm{CO}_{2}$ and natural gas 29 are completely miscible, simulation of potential EGR scenarios is required to determine 30 when breakthrough of $\mathrm{CO}_{2}$ will occur at the natural gas production wells. For such 31 reservoir simulations to be reliable (independent of software used), accurate dispersion data 32 between $\mathrm{CO}_{2}$ and natural gas at relevant reservoir conditions are required. To this end we 33 apply one dimensional (1D) magnetic resonance imaging (MRI) to quantify this dispersion 34 process in-situ in both sandstone and carbonate rock cores. Specifically we apply the 35 SPRITE MRI sequence (Balcom et al. 1996) to facilitate quantitative axial profiles of 36 methane $\left(\mathrm{CH}_{4}\right)$ content during core flooding processes between $\mathrm{CO}_{2}$ and $\mathrm{CH}_{4}$. 37 Simultaneously we measure, using infrared (IR), the effluent $\mathrm{CO}_{2}$ and $\mathrm{CH}_{4}$ concentrations 38 enabling ex-situ dispersion measurements. Via comparison with the corresponding MRI 39 data, the erroneous contributions to dispersion from entry/exit effects and mixing in piping 40 to and from the rock core holder are quantified. Furthermore, we demonstrate how nuclear 41 magnetic resonance (NMR) $T_{2}$ measurements can be uniquely used to probe the pore size 42 occupancy of the $\mathrm{CH}_{4}$ during the core flooding process. 


\section{Introduction}

54 Carbon dioxide $\left(\mathrm{CO}_{2}\right)$ sequestration in suitable geological formations is a 55 promising strategy to mitigate greenhouse gas emission (e.g. Barrufet et al. 2010; Kheshgi 56 et al. 2012; Leung et al. 2014). Injection of $\mathrm{CO}_{2}$ into natural gas reservoirs can not only 57 serve to store $\mathrm{CO}_{2}$ within the formations but also potentially improve natural gas recovery. 58 However, complete miscibility between natural gas and $\mathrm{CO}_{2}$ at all relevant reservoir 59 conditions (Hughes et al. 2012; Honari et al. 2015a, b) is a significant barrier for the 60 application of this enhanced gas recovery (EGR) technology as it potentially results in 61 contamination of, and $\mathrm{CO}_{2}$ breakthrough in, the natural gas product. This has prompted 62 several EGR simulation studies (e.g. Oldenburg et al. 2002; Patel et al. 2016; Patel et al. 63 2017; Pooladi-Darvish et al. 2008) of various reservoir scenarios (probing, for example, 64 the effect of permeability heterogeneity and injection rate) in order to estimate the related 65 risks and uncertainties of $\mathrm{CO}_{2}$ EGR implementation. However, to ensure these simulation 66 studies have a sufficiently high fidelity, an accurate description of the mixing (dispersion) 67 between the $\mathrm{CO}_{2}$ and the $\mathrm{CH}_{4}$ (or natural gas) in a reservoir is required. The dispersion data necessary for these reservoir simulations is accessible via laboratory-scale core flooding measurements using cylindrical rock core samples (e.g. Hughes et al. 2012; Honari et al. 2015a, b; Honari et al. 2016; Zecca et al. 2017; Zhang et al. 2016; Yu et al. 1999).

Whilst core-scale measurements of dispersion are in principle transferable to the reservoir scale, these laboratory measurements are nevertheless notoriously difficult to execute and can suffer from many systematic errors including erroneous contributions to mixing that occur both due to entry and exit effects into the rock core sample as well as in

76 piping to and from the rock core holder. Previously we have applied 1D Magnetic

77 Resonance Imaging (MRI) to quantify such gas-phase $\mathrm{CO}_{2}-\mathrm{CH}_{4}$ mixing in-situ in a model

78 glass bead random packing (Honari et al. 2015b); here we extend this to actual rock cores 79 at conditions more relevant to the reservoir (supercritical fluids and 100 bar pore pressure 80 versus 45 bar pore pressure). We also complement these dispersion experiments with 81 Nuclear Magnetic Resonance (NMR) $T_{2}$ relaxometry measurements of pore size 82 occupation by the methane during the core flooding process. 
NMR and MRI have been widely employed to measure a range of transport properties of various fluids in porous media including various hydrocarbons in rock cores (e.g. Mitchell et al. 2013; Coates et al. 1999; Zhao et al. 2016; Ramskill 2018; Li et al. 2016; Li et al. 2017a, b; Mitchell et al. 2018; Shikhov et al. 2018). Whilst these have predominately focused on liquid phase measurements, due predominately to signal-tonoise (SNR) considerations, gas phase NMR/MRI has been used; for example by Zecca et al. (2018), to determine the restricted diffusion coefficient of ethane in sandstone cores and, hence, their tortuosity. It has also, for example, been used by Cheng et al. (2005) to study ${ }^{13} \mathrm{CO}_{2}$ density profiles in a zeolite bed during adsorption/desorption processes. Shikhov and Arns (2017) employed NMR gas diffusion to determine tortuosity as a function of both position along the rock core and fluid saturation. Away from the laboratory, Akkurt et al. (1996) employed NMR technology to log natural gas reservoirs and found that NMR provided hydrocarbon saturation results that were consistent with conventional methods. An elegant review of gas flow measurements by NMR/MRI is provided by Newling (2008).

Dispersion is a physical blending phenomenon due to both molecular diffusion and fluid advection and consequential mixing (Blackwell 1962), the latter effect being a strong function of the rock matrix heterogeneity at multiple length-scales. Dispersion is generally quantified by a dispersion coefficient, $K$ (Taylor et al. 1954). In the context of the $\mathrm{CO}_{2}$ EGR process, the dispersion process between the injected $\mathrm{CO}_{2}$ fluid phase and the nascent $\mathrm{CH}_{4}$ phase, is affected by the rock matrix heterogeneity (Blok et al. 1997; Honari et al. 2015a), the presence of connate water (Zecca et al. 2017; Zhang et al. 2016), reservoir pressure and temperature (via their resulting impact on fluid viscosity, density and diffusion coefficient) (Hughes et al. 2012), and fluid injection flow rate (Hughes et al. 2012; Zecca et al. 2017; Zhang et al. 2016; Honari et al. 2015a). As a consequence of both practical limitations on injection volumetric flowrate and an increasing front area as the $\mathrm{CO}_{2}$ migrates away from the injection well, the vast majority of the dispersion process throughout the whole reservoir occurs at very low flow rates. Consequently here we will consider only comparatively slow displacement velocities.

In the current work, $1 \mathrm{D}$ axial MRI measurements were employed to monitor $\mathrm{CH}_{4}$ and $\mathrm{CO}_{2}$ core flooding processes in both sandstone and carbonate rock cores. The SPRITE MRI pulse sequence (Balcom et al. 1996) was employed as it provides better NMR signal 
114 homogeneity than the spin echo MRI method along the core axis. The MRI measurements

115 determine the $\mathrm{CH}_{4}$ content along the axis of the rock cores as a function of time and hence

116 injection volume. By suitable evaluation of the evolution of these 1D axial profiles as a

117 function of injection time, it is possible to extract the value of the dispersion coefficient

118 quantifying the mixing process. As the measurement is performed in-situ, any erroneous 119 contribution to mixing due to core entry/exit effects and piping to and from the core are 120 effectively eliminated. The scale of these erroneous contributions is quantified by 121 simultaneously monitoring the core flooding apparatus effluent $\mathrm{CO}_{2}$ and $\mathrm{CH}_{4}$ 122 concentrations using ex-situ infrared (IR) measurements. Dispersion measurements were 123 performed for both $\mathrm{CO}_{2}$ displacing $\mathrm{CH}_{4}$ and $\mathrm{CH}_{4}$ displacing $\mathrm{CO}_{2}$. Simultaneously, NMR $124 T_{2}$ relaxation time measurements were performed to quantify the pore size occupancy by 125 the $\mathrm{CH}_{4}$ during the core flooding.

1272 Theoretical Background

\section{$128 \quad 2.1$ Dispersion in porous media}

129

130

132

133 134 135

141

Dispersion in a porous medium is a physical mixing process (Delgado et al. 2007) in which molecular diffusion and mechanical advection dominate the dispersion at low and high flow velocities, respectively, bookending a transition zone in which both effects make a significant contribution (Honari et al. 2015a; Hughes et al. 2012). Both transverse and longitudinal dispersion processes in porous media have been studied for many decades in a variety of fields including soil, groundwater, and petroleum engineering. When mechanical advection dominates, longitudinal dispersion is generally approximately an order of magnitude larger than transverse dispersion (Delgado et al. 2007); when molecular diffusion is dominant, longitudinal and transverse dispersion are approximately equal (Delgado et al. 2007).

The longitudinal dispersion coefficient $\left(K_{\mathrm{L}}\right)$ is described by a one dimensional (1D) advective-dispersion (AD) equation (Taylor et al. 1953; Taylor et al. 1954):

$$
\frac{\partial C}{\partial t}=K_{\mathrm{L}} \frac{\partial^{2} C}{\partial x^{2}}-u \frac{\partial C}{\partial x}
$$


142 where $C$ is the concentration (mole fraction) of the dispersing species, $u$ is mean flow 143 velocity, $t$ is time and $x$ is axial position along the porous media. The solution to Equation 144 (1) with the boundary conditions $C(t=0, x>0)=0, C(t=0, x=0)=1$, and $C(t, \infty)=0$ is (Seo 145 et al. 2005; Honari et al. 2015a; Hughes et al. 2012):

$$
C=\frac{1}{2}\left[\operatorname{erfc}\left(\frac{x_{\mathrm{D}}-t_{\mathrm{D}}}{2 \sqrt{t_{\mathrm{D}} / P e_{\exp }}}\right)+\exp \left(x_{\mathrm{D}} P e_{\exp }\right) \operatorname{erfc}\left(\frac{x_{\mathrm{D}}+t_{\mathrm{D}}}{2 \sqrt{t_{\mathrm{D}} / P e_{\exp }}}\right)\right],
$$

where $x_{\mathrm{D}}=x / L_{\exp }, t_{\mathrm{D}}=u t / L_{\mathrm{exp}}, L_{\exp }$ is the length of the rock core plug, and the experimental Péclet number is defined as $P e_{\exp }=u L_{\exp } / K_{\mathrm{L}}$.

Generally, $C$ is measured at the exit of a cylindrical rock core following either a step increase in $C$ or a pulse of the dispersing species being injected into the flow at the rock core entry (Honari et al. 2015a; Hughes et al. 2012; Zecca et al. 2017; Yu et al. 1999); this process is effectively core flooding. As previously mentioned however mixing of the injected species and the nascent species can occur in piping to and from the rock core as well as a consequence of entry and exit effects into the rock core itself. A number of approaches have been proposed in the literature to deal with this erroneous contribution (e.g. Honari et al. 2015b; Hughes et al. 2012; Edwards et al. 1968; Rajendran et al. 2008). A simple correction is to perform the core flooding measurements with and without the porous media being present followed by subtraction of the erroneous mixing contribution (Edwards et al. 1968; Guntuka et al. 2008); this of course assumes that the contributions are linearly additive (Rajendran et al. 2008). Hughes et al. (2012) demonstrated a 'long core and short core' method, which was improved upon by Zecca et al. (2017), to correct for these erroneous effects in which the dispersion of the short core was used as the input to the dispersion occurring in the additional length of the longer core. The erroneous contribution should be identical for both cores and thus is effectively eliminated. The method however assumes that the exit and entry effects are identical and simply additive. Honari et al. (2015b) employed MRI to monitor $\mathrm{CH}_{4}$ displacements by $\mathrm{CO}_{2}$ in a model glass bead packing, in the process measuring the evolution in the $\mathrm{CH}_{4}$ concentration along the core length. The in-situ effective breakthrough curve measured at an upstream position was used to estimate the in-situ effective breakthrough curve further downstream with $K_{\mathrm{L}}$ as the fitting parameter. Erroneous mixing in the inlet was completed captured by the 
171 upstream in-situ effective breakthrough curve; erroneous mixing at the outlet was irrelevant 172 to these measurements. The method of Honari et al. (2015b) was adopted by Zhang et al. 173 (2016), who measured dispersion in a sand packing using X-ray CT images of the gas axial 174 concentration distribution.

175

176

177

178

179

180

181

182

184

185 186

\subsection{Pore scale fluid characterization using $T_{2}$ measurements}

$T_{2}$ relaxation time distributions are frequently employed to characterize fluids in rock core samples (e.g. Mitchell et al. 2013; Li et al. 2017a; Coates et al. 1999). When $T_{2}$ measurements are performed using low magnetic field strengths and short echo times, the following expression can be employed to describe $T_{2}$ (Muir and Balcom 2012):

$$
\frac{1}{T_{2}}=\frac{1}{T_{2, \text { Bulk }}}+\frac{1}{T_{2, \text { Surf }}}
$$

where $T_{2, \text { Bulk }}$ is the bulk transverse relaxation time and $T_{2, \text { Surf }}$ is the surface transverse relaxation time. Equation (3) assumes that background magnetic field gradients due to susceptibility differences between the rock matrix and the pore fluid are minimal (Mitchell et al. 2010; Connolly et al. 2017). The surface relaxation rate $\left(1 / T_{2, \text { Surf }}\right)$ of the fluid in a pore in the fast-diffusion limit is given by (Freedman et al. 2003):

$$
\frac{1}{T_{2, \text { Surf }}}=\rho_{2}\left(\frac{S}{V}\right) \text {, }
$$

where $\rho_{2}$ is the surface relaxivity, $S$ is the contact area of the fluid and pore surface, and $V$ is the volume of the fluid. Assuming that $T_{2 \text {,surf }}<<T_{2, \text { bulk }}$, the pore size can be approximated based on Equation (4) on the assumption of a spherical pore geometry, in which case the representative pore radius, $R$, is estimated as:

$$
R=3 \rho_{2} T_{2}
$$

where $\rho_{2}$ values are approximately $18.2 \mu \mathrm{m} / \mathrm{s}$ and $9.6 \mu \mathrm{m} / \mathrm{s}$ for water saturated Berea sandstone and carbonate samples, respectively, based on the mean of available literature data (e.g. Mesquita et al. 2016; Johnson 2015; Carneiro et al. 2014).

\section{Methodology}




\subsection{Materials and experimental setup}

High purity $\mathrm{CH}_{4}(\geq 99.995 \%)$ and $\mathrm{CO}_{2}(\geq 99.995 \%)$ were supplied by Coregas Pty

Ltd (Western Australia, Australia). Fluorinated oil (FC-40) was purchased from 3M company (MN, USA), and was used for the application of confining pressure to the rock cores. A Berea sandstone and a carbonate (Silurian dolomite purchased from Kocurek industries, TX, USA) core plugs were employed in this work. Table 1 lists their physical 203 properties.

Figure 1 shows a schematic of the experimental apparatus for NMR/MRI and IR monitoring of the gas flooding processes in the core plugs. An NMR compatible core holder (FCH-1.0: S2 Glass and PEEK, Core Laboratories, OK, USA) rated to 345 bar pressure was used for these experiments. Two syringe pumps, pump 2, (260D Teledyne ISCO, NE, USA) and pump 3, (Quizix QX-6000SS Chandler Engineering, OK, USA) were employed for $\mathrm{CO}_{2}$ and $\mathrm{CH}_{4}$ injection, respectively. A vacuum pump (949-9315 Agilent Technologies, Torino, Italy) was used to evacuate the rock core samples. Another syringe pump (pump 4, 260D Teledyne ISCO) was connected to the end of the flooding system to provide back pressure control. Pump 1 was a hydraulic pump (87-6-5, High Pressure Equipment Company, PA, USA) filled with the fluorinated oil (FC-40) used for the confining pressure of the rock cores via the core holder. $\mathrm{CH}_{4}$ spin density and relaxation measurements were exclusively performed using a $0.3 \mathrm{~T}$ Maran Ultra permanent magnet spectrometer (Oxford Instruments, U.K.) operating at $12.9 \mathrm{MHz}{ }^{1} \mathrm{H}$ resonance frequency and equipped with 3D gradient coils. IR measurements of the effluent were conducted with a Varian 640 IR spectrometer located before the pump controlling the back pressure. For the $\mathrm{CO}_{2}$ displacing $\mathrm{CH}_{4}$ experiments, flow through the rock core was directed in a vertical direction; this was reversed for $\mathrm{CH}_{4}$ displacing $\mathrm{CO}_{2}$. This ensured that the fluid with the greater density was at the bottom and thus prevented erroneous mixing due to buoyancy

223 by Hughes et al. (2012).

\subsection{Experimental procedure}


The core plugs were dried at $120{ }^{\circ} \mathrm{C}$ until their weight stopped decreasing over 24

227 hours and were then mounted into the NMR compatible core holder. The core holder was 228 placed in the magnet chamber and connected to the pumps and the IR spectrometer as 229 indicated in Figure 1. A confining pressure of 50 bar was applied using pump 1; the vacuum pump was then used to remove air from the rock core. For $\mathrm{CH}_{4}$ displacement by $\mathrm{CO}_{2}, \mathrm{CH}_{4}$ was first introduced into the core plug by gradually increasing its pressure whilst the

233 the $\mathrm{CH}_{4}$ pressure was kept at approximately 50 bar. $\mathrm{CH}_{4}$ injection was stopped when there 234 was approximately $15 \mathrm{ml}$ of $\mathrm{CH}_{4}$ in the back pressure pump (pump 4) which was operated 235 in constant pressure mode with a set point of 100 bar. The confining pressure was then 236 increased to 160 bar. The NMR/MRI and IR measurements were then commenced 237 followed by $\mathrm{CO}_{2}$ flooding. The $\mathrm{CO}_{2}$ flooding process was completed when the IR signal 238 for $\mathrm{CH}_{4}$ measured at the core exit was zero.- These flooding experiments were conducted 239 over a range of displacement velocities. For the experiments where $\mathrm{CH}_{4}$ was injected into $240 \mathrm{CO}_{2}$ saturated rock cores, the process was effectively performed in reverse. All the 241 combined NMR/MRI and IR measurements of the core flooding process, were performed 242 at a temperature of $20{ }^{\circ} \mathrm{C}$ and a pressure of 100 bar; at these conditions the $\mathrm{CO}_{2}$ is a 243 compressed liquid. Core flooding with only IR analysis of the effluent was performed at $244 \quad 40{ }^{\circ} \mathrm{C}$ and 100 bar.

\subsection{MRI and NMR Experiments}

In comparison with the experiments presented in Honari et al. (2015b), the current 248 measurements are significantly more challenging in terms of signal-to-noise ratio (SNR) 249 due primarily to the comparatively much lower rock core porosity. Honari et al. (2015b) 250 employed a 1D spin-echo MRI pulse sequence to measure the $\mathrm{CH}_{4}$ axial concentration 251 profile in a model porous medium. Here we employ a more readily quantitative 1D Single 252 Point Ramped Imaging with $T_{1}$ Enhancement (SPRITE) MRI pulse sequence (Balcom $e t$ 253 al. 1996), which is more immune to $B_{1}$ imperfections. Figure 2(a) shows 1D MRI axial 254 profiles of a $3 \mathrm{~cm}$ diameter bottle of water acquired using both conventional spin-echo and 255 SPRITE MRI pulse sequences. A more homogeneous axial profile reflecting the expected 
256 bottle shape is observed from the SPRITE measurement; therefore it was employed to 257 monitor core flooding processes in this study. The field of view (FOV) of the two profiles 258 was $12 \mathrm{~cm}$ and a resolution of $1.9 \mathrm{~mm}$. The signal intensity of the SPRITE pulse sequence 259 is impacted not only by the concentration of the $\mathrm{CH}_{4}$ but also its $T_{1}$ and $T_{2}{ }^{*}$ signal relaxation 260 times (Balcom et al. 1996). Four mixtures of $\mathrm{CO}_{2}$ and $\mathrm{CH}_{4}\left(\mathrm{CH}_{4}\right.$ molar concentrations of $2.4 \%, 33.5 \%, 65.4 \%$, and $98.0 \%$, respectively) were prepared and pumped into a dry Berea 262 core plug at 100 bar. Figure 2(b) shows the total SPRITE signal intensity against the mole 263 fraction of $\mathrm{CH}_{4}$ (repeated twice). There is a reasonable linear correlation and no evidence 264 of systematic bias due to NMR relaxation effects. The SPRITE MRI measurement error is 265 estimated at $4 \%$ based on the repeat measurements in Figure 2(b).

266 A standard Carr-Purcell-Meiboom-Gill (CPMG) pulse sequence was also 267 employed to determine the $T_{2}$ distribution of $\mathrm{CH}_{4}$ in the rock core plugs. For low flooding 268 rates $(\leq 0.1 \mathrm{ml} / \mathrm{min})$, the CPMG and the SPRITE MRI measurements were interleaved. For 269 higher flooding rates (>0.1 ml/min), only SPRITE MRI measurements were performed 270 due to the rapid change in gas concentrations during the core flooding process. All 271 NMR/MRI measurement parameters are reported in Table 2.

\section{3.4 Dispersion Data Analysis}

In this work, the $K_{\mathrm{L}}$ correction method of Honari et al. (2015b) based on MRI measurements was employed. The effective breakthrough profile measured in the front half

276 section $(x=1.9 \mathrm{~cm})$ of the rock core was used as an input to Equation (1) to determine the 277 effective breakthrough curve of the core rear half section $(x=5.7 \mathrm{~cm})$, with $K_{\mathrm{L}}$ as the fitting 278 parameter; $x$ is the axial position along the rock core from the core entry $(x=0 \mathrm{~cm})$. 279 Equation (1) was solved numerically using a central finite difference method in Matlab 280 (version R2016b).

Based on data in Takahashi and Iwasaki (1970) which span the range (25 to 75) ${ }^{\circ} \mathrm{C}$ 282 and (50 to 150) bar, Hughes et al. (2012) fitted the following correlation for the molecular 283 diffusion coefficient of $\mathrm{CO}_{2}$ in $\mathrm{CH}_{4}\left(D_{\mathrm{CO}_{2}, \mathrm{CH}_{4}}\left(\mathrm{~m}^{2} / \mathrm{s}\right)\right)$ : 


$$
D_{\mathrm{CO}_{2}, \mathrm{CH}_{4}}=\frac{\left(-4.3844 \times 10^{-13} p+8.5440 \times 10^{-11}\right) T^{1.75}}{p},
$$

285

286

where $p$ and $T$ are pressure (MPa) and temperature (K), respectively. Equation (6) was shown to be consistent with core flooding data (Hughes et al. 2012). We were not able to locate equivalent, relevant data for the diffusion coefficient of $\mathrm{CH}_{4}$ in $\mathrm{CO}_{2}$.

\section{Results and Discussion}

\subsection{Sample Core Flooding Data}

Figure 3 shows an example set of breakthrough curves for $\mathrm{CO}_{2}$ flooding to displace $\mathrm{CH}_{4}$ and $\mathrm{CH}_{4}$ flooding to displace $\mathrm{CO}_{2}$ in both a carbonate core plug and the core holder without a core sample present - these were acquired ex-situ using IR measurements in the high pressure core flooding apparatus. The core flooding experiments shown in Figure 3 were undertaken at $40{ }^{\circ} \mathrm{C}$ and 100 bar at a flow rate of $2 \mathrm{ml} / \mathrm{min}$. The mole fraction of $\mathrm{CO}_{2}$, $y_{\mathrm{CO}_{2}}$, increases more rapidly during $\mathrm{CO}_{2}$ flooding than the increase of the $\mathrm{CH}_{4}$ mole fraction, $y_{\mathrm{CH}_{4}}$, during $\mathrm{CH}_{4}$ flooding, resulting in a sharper breakthrough profile and a slightly shorter overall $\mathrm{CO}_{2}$ flooding time. This difference may be partially attributed to the gas viscosities of $4.77 \times 10^{-5} \mathrm{~Pa} \cdot \mathrm{s}$ for $\mathrm{CO}_{2}$ and $1.39 \times 10^{-5} \mathrm{~Pa} \cdot \mathrm{s}$ for $\mathrm{CH}_{4}$ at $40{ }^{\circ} \mathrm{C}$ and $100 \mathrm{bar}$ (Lemmon et al. 2018; Laesecke et al. 2017), which results in a more favorable viscosity ratio for 'pistonlike' $\mathrm{CO}_{2}$ flooding to displace $\mathrm{CH}_{4}$ (Brigham et al. 1961; Xia et al. 2016). A lag or slow growth region is also evident between 40 and 80 minutes for $\mathrm{CH}_{4}$ flooding. This we attribute to stagnant region in the core holder when flooding from above.

In Figure 3, the gray dashed line corresponds to an 'ideal' situation in which gas displacement occurs instantaneously i.e. it is the input boundary condition leading to the solution shown in Eq. (2). Clearly this is substantially different to the breakthrough profiles obtained with no rock core sample for two main reasons. First, the time delay between them ( 10 minutes) is a consequence of the residence time in the system tubing, which has a total volume of around $20 \mathrm{ml}$. Second, the breakthrough profile shape obtained for the system without a sample is not instantaneous and exhibits a small degree of spreading. This is a consequence of the erroneous contribution to mixing that occurs in the tubing to and 
312 from the rock core holder in addition to entry and exit effects through the distribution plugs

313 of the rock core holder, which is consistent with the observations of Hughes et al. (2012).

314 Our MRI measurements, by virtue of their in-situ characteristic, directly account for this

315 contribution to the observed mixing via the input breakthrough profile for Equation (1).

\subsection{MRI Concentration Profiles}

Figure 4 shows only six sample time-resolved $1 \mathrm{D} \mathrm{CH}_{4}$ axial concentration profiles for each series of measurements in the two core plugs (sandstone and carbonate) for the sake of clarity for both $\mathrm{CH}_{4}$ flooding and $\mathrm{CO}_{2}$ flooding as acquired using SPRITE MRI; a value of 1 corresponds to the mean $\mathrm{CH}_{4}$ signal for the whole rock core when it contained only $\mathrm{CH}_{4}$. In each case, only six profiles are shown, many more profiles were acquired (every 1.7 minutes) during the core flooding processes. The signal intensity of each profile represents the temporally average $\mathrm{CH}_{4}$ concentration along the rock core over the total MRI profile measurement time of 1.7 minutes. Prior to, and following flooding, a series of five repeat profiles were acquired when the core was saturated with $\mathrm{CH}_{4}$. This data was used to generate standard deviations and hence error bars which are reported for the equivalent data in Figure 4.

The flooding rate in Figure 4 was consistently $0.5 \mathrm{ml} / \mathrm{min}$ (at 100 bar and $20^{\circ} \mathrm{C}$ ). The profiles have a relatively low SNR as dictated by the limited MRI signal and the need to perform the profile measurements rapidly such that they did not significantly blur due to signal displacement as core flooding progressed during the profile acquisition temporal window. Nevertheless certain trends are distinctly obvious.

Figure 4(a) shows the result for $\mathrm{CO}_{2}$ flooding to displace $\mathrm{CH}_{4}$ in the Berea sandstone core plug. The $\mathrm{CH}_{4}$ concentration (MRI Signal) gradually decreased from the core plug inlet to the outlet as it was progressively displaced. The opposite is observed in Figure 4(b) as $\mathrm{CO}_{2}$ was displaced by $\mathrm{CH}_{4}$ from the rock core. The breakthrough of the displacing fluid was deemed to occur when the $\mathrm{CH}_{4} \mathrm{MRI}$ signal intensity at $x=7.6 \mathrm{~cm}$ commenced to decrease $\left(\mathrm{CO}_{2}\right.$ flooding $)$ or increase $\left(\mathrm{CH}_{4}\right.$ flooding $)$ consistently over three successive measurements. In the Berea sandstone core plug, $\mathrm{CO}_{2}$ breakthrough at the rock core exit occurred at $\sim 31$ minutes during $\mathrm{CO}_{2}$ flooding whilst $\mathrm{CH}_{4}$ breakthrough occurred 
342 at 26 minutes during $\mathrm{CH}_{4}$ flooding. The earlier $\mathrm{CH}_{4}$ breakthrough than $\mathrm{CO}_{2}$ may be 343 attributed to the comparatively lower $\mathrm{CH}_{4}$ viscosity, and is consistent with the results of 344 Brigham et al. (1961) for example which showed earlier breakthrough when a lower 345 viscosity fluid was injected into a porous medium. Figures 4(c) shows the corresponding $3461 \mathrm{D} \mathrm{CH}_{4}$ concentration profiles in the carbonate core plug during $\mathrm{CO}_{2}$ flooding. The initial 347 distribution is much less uniform than the sandstone core, reflecting the greater 348 heterogeneity of carbonates as widely reported in the literature (e.g. Lucia et al. 2003; 349 Ehrenberg 2005). The $\mathrm{CH}_{4}$ is gradually removed from the carbonate rock core with no obvious displacement front as was the case for the Berea sandstone. However a comparatively more rapid $\mathrm{CO}_{2}$ breakthrough is observed at $\sim 27$ minutes - indicating that this is predominately controlled by the lower porosity of the carbonate (17\% versus $20 \%$ 353 for the Berea sandstone - Table 1). This is also broadly the case for $\mathrm{CH}_{4}$ flooding of the 354 carbonate core in Figure 4(d) which presented a breakthrough time of 20 minutes.

\subsection{Dispersion Coefficient Data}

Figure 5 shows a sample set of $\mathrm{CO}_{2}$ and $\mathrm{CH}_{4}$ breakthrough curves in the Berea core plug as independently determined by SPRITE MRI (both at $x=1.9 \mathrm{~cm}$ and $x=5.7 \mathrm{~cm}$ ) and $e x$-situ via IR measurements. The core flooding processes were conducted with a flooding rate of $0.5 \mathrm{ml} / \mathrm{min}(u=0.0829 \mathrm{~mm} / \mathrm{s})$ at $20{ }^{\circ} \mathrm{C}$ and $100 \mathrm{bar}$. The IR data were fit using the analytical solution provided by Equation (2) using the apparent dispersion coefficient, $K_{\mathrm{L}}$, 362 as a fitting parameter. The MRI data at $x=5.7 \mathrm{~cm}$ is fit using Equation (1) (as solved numerically using Matlab) using the experimental data at $x=1.9 \mathrm{~cm}$ as an input, as outlined 364 above.

In Figure 5, the relative delay in gas breakthrough times for the IR measurements reflects that they are acquired significantly after the fluid has exited the core. Whilst there is greater scatter in the MRI data the fits are reasonably good. In Figure 5(a), for the IR data, a systematic deviation between the fit and the experimental data becomes evident at around 100 minutes. This we attribute to stagnant regions in the core holder which are accentuated when the core is flooded with $\mathrm{CH}_{4}$ from above relative to $\mathrm{CO}_{2}$ flooding from

371 below. This discrepancy is not evident in the corresponding MRI data indicating that 
372 performing the measurements in-situ has facilitated elimination of this erroneous effect.

373 A similar observation was evident with respect to the corresponding carbonate data. numerically to the MRI data $(x=5.7 \mathrm{~cm})$ and fitting Equation $(2)$ to the IR data are shown

376 in Figure 6 for all measurements performed on both the sandstone and the carbonate rock 377 core as a function of superficial displacement velocity. It is immediately obvious that the 378 MRI data result in lower values of $K_{\mathrm{L}}$ relative to the corresponding IR data. This is most 379 evident for the $\mathrm{CH}_{4}$ flooding measurements and is consistent with the observations with respect to Figure 5 where the IR breakthrough curves were obviously adversely affected by contributions to mixing from tube mixing and input/output effects. Nonetheless the MRI data still clearly shows elevated values of $K_{\mathrm{L}}$ for the $\mathrm{CH}_{4}$ flooding relative to the $\mathrm{CO}_{2}$ flooding in both rock cores. At 100 bar and $20{ }^{\circ} \mathrm{C}$, the viscosities of $\mathrm{CO}_{2}$ and $\mathrm{CH}_{4}$ are $8.25 \times 10^{-5} \mathrm{~Pa} \cdot \mathrm{s}$ and $1.37 \times 10^{-5} \mathrm{~Pa} \cdot \mathrm{s}$, respectively, (Lemmon et al. 2018; Laesecke et al. 2017) and as discussed previously the more favorable viscosity ratio for 'piston like' displacement for $\mathrm{CO}_{2}$ flooding results in reduced mixing and a lower value of $K_{\mathrm{L}}$. The $K_{\mathrm{L}}$ values of $\mathrm{CO}_{2}$ in carbonate $\left(5 \sim 50 \times 10^{-8} \mathrm{~m}^{2} / \mathrm{s}\right)$ were also generally higher than $K_{\mathrm{L}}$ in Berea $\left(5 \sim 25 \times 10^{-8} \mathrm{~m}^{2} / \mathrm{s}\right)$, which is consistent with data presented in Honari et al. (2015a).

Figure 6 also presents the diffusion coefficient of $\mathrm{CO}_{2}$ in $\mathrm{CH}_{4}$ (as obtained from the literature (Hughes et al. (2012), Takahashi and Iwasaki (1970)): $1.7 \times 10^{-7} \mathrm{~m}^{2} / \mathrm{s}$ at $100 \mathrm{bar}$ and $20^{\circ} \mathrm{C}$. As expected the acquired SPRITE data are consistent with this diffusion value, 392 indicating that the $\mathrm{CO}_{2}$ dispersion measurements were performed predominately in the 393 diffusion-dominated regime. The diffusion coefficient of $\mathrm{CH}_{4}$ in $\mathrm{CO}_{2}$ at the same pressure 394 and temperature condition (100 bar and $\left.20^{\circ}\right)$ is at least significantly less than $6.8 \times 10^{-8} \mathrm{~m}^{2} / \mathrm{s}$ 395 (based on data in Takahashi (1972) for a pressure of 49 bar)). Higher displacement 396 velocities are difficult to access whilst still allowing for adequate time for MRI profiling; 397 however as discussed above the diffusion-dominated regime is most relevant to $\mathrm{CO}_{2}$ 398 dispersion in EGR reservoir simulations.

\subsection{Pore scale fluid behavior}


In this study, CPMG measurements were performed to monitor the pore size occupation of $\mathrm{CH}_{4}$ during the core flooding processes when the flooding rates were low ( $\leq$ $0.1 \mathrm{ml} / \mathrm{min}$ ) by determining $T_{2}$ relaxation time distributions. After the core flooding experiments, $T_{2}$ measurements were also undertaken for the two rock core plugs when fully saturated with brine solution to estimate the pore size distribution according to Equation (5) using literature $\rho_{2}$ values as reported above. Figure 7 shows the resultant $T_{2}$ relaxation (and pore size) distributions of the Berea and carbonate rocks when fully saturated with brine solution. The $T_{2}$ distribution of the core plug fully saturated with $\mathrm{CH}_{4}$ and the $T_{2}$ distribution of the same core plug fully saturated with brine (and hence the pore size distribution) were then compared. Both were converted to pore size distributions using 411 Equation (5) and the difference or error between the two pore size distributions was minimized by adjusting $\rho_{2}$ for $\mathrm{CH}_{4}$. This resulted in $\rho_{2}$ for $\mathrm{CH}_{4}$ in the Berea and carbonate rocks being estimated at $33 \mu \mathrm{m} / \mathrm{s}$ and $26 \mu \mathrm{m} / \mathrm{s}$, respectively.

Figure 8 shows $T_{2}$ relaxation time distributions and consequential estimated pore size distributions of $\mathrm{CH}_{4}$ in the Berea and carbonate core plugs during the gas flooding 416 processes. For the $\mathrm{CO}_{2}$ displacement by $\mathrm{CH}_{4}$ in Berea shown in Figure 8(a), the signal 417 intensity gradually increased as the $\mathrm{CH}_{4}$ concentration increased during the core flooding. 418 The mean $T_{2}$ progressively shifted from about $45 \mathrm{~ms}$ to about $25 \mathrm{~ms}$. The $T_{2}$ of bulk $\mathrm{CH}_{4}$ $419\left(y_{\mathrm{CH}_{4}}=1\right)$ and a gaseous mixture of $\mathrm{CH}_{4}$ and $\mathrm{CO}_{2}\left(y_{\mathrm{CH}_{4}}=0.52\right)$ were measured to be 1.37 and 1.39 seconds, respectively, both of which are much longer than the $T_{2} \mathrm{Of}_{\mathrm{CH}_{4}}$ in the rock.

421 Therefore, the $T_{2}$ of gas in the rock is dominated by surface relaxation $T_{2 \text {,surf }}$ (as detailed in 422 Equation (3)), meaning that Equation (5) is valid. According to the correlation between

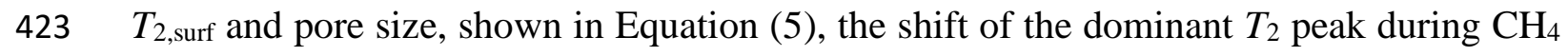
424 flooding indicates that $\mathrm{CH}_{4}$ firstly preferentially entered larger pores to displace $\mathrm{CO}_{2}$. 425 During the $\mathrm{CH}_{4}$ displacement by $\mathrm{CO}_{2}$ in the Berea core plug (Figure 8(b)), the $T_{2}$ 426 distribution signal intensity decreases as expected; however the $T_{2}$ peak shifts to larger 427 values indicating that the residual $\mathrm{CH}_{4}$ occupies preferentially larger pores. Similar $\mathrm{CH}_{4} T_{2}$ 428 distribution variations to this Berea sample were observed for the carbonate samples 429 (Figure 8(c) and (d)). A significant difference between the two rocks is that the $T_{2}$ values 430 were longer ( $100 \mathrm{~ms})$ for carbonate than for Berea ( $30 \mathrm{~ms})$; the validity of Equation (5) 431 nevertheless remains intact. This difference is a consequence of both weaker surface 
432 relaxivity (Chang et al. 1994; Timur et al. 1972) and larger pore size in carbonates 433 compared to sandstones.

434 Figure 9 shows the $T_{2} \log$ mean $\left(T_{2 \mathrm{LM}}\right)$ of the $\mathrm{CH}_{4}$ signal plotted as a function of $435 \mathrm{CH}_{4}$ mole fraction, $y_{\mathrm{CH}_{4}}$. For both Berea and carbonate, $T_{2 \mathrm{LM}}$ decreased with the increase of $436 y_{\mathrm{CH}_{4}}$ indicating preferential occupation of larger pores by the $\mathrm{CH}_{4}$. The curves were identical 437 for the carbonate for both $\mathrm{CO}_{2}$ and $\mathrm{CH}_{4}$ flooding. This was not the case for the Berea, the 438 reason for this hysteresis is currently unclear and will be explored further in future work. 439 Assumptions with respect to the data in Figures 8 and 9 are that the pores are spherical in 440 shape and that the reduction in $T_{2}$ used for pore size occupation is a consequence only of 441 surface relaxation (as per Equation 5) and not diffusion in background gradients (Connolly 442 et al. 2019) or as a consequence of local $\mathrm{CH}_{4}-\mathrm{CO}_{2}$ composition. Future work will 443 concentrate on further exploration of these assumptions via, for example, spatially resolved $444 T_{2}$ distribution measurements using, for example spin-echo single point imaging (SE-SPI) 445 (Xiao et al. 2014).

\section{Conclusions}

SPRITE axial 1D MRI measurements were employed to monitor the displacement 449 processes in Berea and carbonate rock core plugs. Displacement of $\mathrm{CH}_{4}$ by $\mathrm{CO}_{2}$ and the 450 displacement of $\mathrm{CO}_{2}$ by $\mathrm{CH}_{4}$ were both axially profiled and used to evaluate the dispersion 451 behaviors of $\mathrm{CO}_{2}$ and $\mathrm{CH}_{4}$ in rock cores free from erroneous entry and piping mixing 452 effects. The extent of these erroneous contributions was evident when the resultant 453 dispersion data were compared against conventional analysis of IR data acquired at the 454 core holder exit. This discrepancy was greater for $\mathrm{CH}_{4}$ displacing $\mathrm{CO}_{2}$. $\mathrm{NMR}_{2}$ 455 distributions were acquired for the $\mathrm{CH}_{4}$ during the displacement process and related to pore 456 size occupation. This revealed the preferential occupation of larger pores by the $\mathrm{CH}_{4}$ 457 during both displacement processes.

\section{Acknowledgements}


461 Project DP170101108.

462 
Table 1 Physical properties of core plugs

\begin{tabular}{lcccc}
\hline Rock Core & $\begin{array}{c}\text { Length } \\
(\mathrm{cm})\end{array}$ & $\begin{array}{c}\text { Diameter } \\
(\mathrm{cm})\end{array}$ & $\begin{array}{c}\text { Permeability } \\
(\mathrm{mD})\end{array}$ & Porosity \\
\hline Berea & 7.6 & 2.5 & 100 & 0.20 \\
Carbonate & 7.7 & 2.5 & 70 & 0.17 \\
\hline
\end{tabular}

464

465

466

467

468

469

470

471

472

473

474

475

476

477

478

479

480

481

482

483

484

485 
Table 2 NMR and MRI measurement parameters 1D SPRITE MRI

RF pulse length $(\mu \mathrm{s}) \quad 3$

RF pulse flip angle (deg) $\quad 18$

encoding time $(\mu s) \quad 94$

field of view (cm) 24

Total number of pixel in $\quad 64$

profile

Resolution (mm) $\quad 3.8$

repetition delay $(\mathrm{s}) \quad 0.6$

number of averages

(high low flooding rates)

32 192

imaging time (min)

(high low flooding rates)

$0.6 \sim 3.8$

Maximum gradient used

(Gauss/cm)

9.7

\begin{tabular}{lc}
\hline \multicolumn{1}{c}{ CPMG } & \\
$90^{\circ}$ pulse length $(\mu \mathrm{s})$ & 14.6 \\
$180^{\circ}$ pulse length $(\mu \mathrm{s})$ & 29.2 \\
relaxation delay $(\mathrm{s})$ & 5.7 \\
number of averages & $16($ Berea $)$ \\
echo time $(\mu \mathrm{s})$ & 12 (Carbonate) \\
number of echoes & 400 \\
& $800($ Berea $)$ \\
\hline
\end{tabular}

487

488

489

490

491

492 


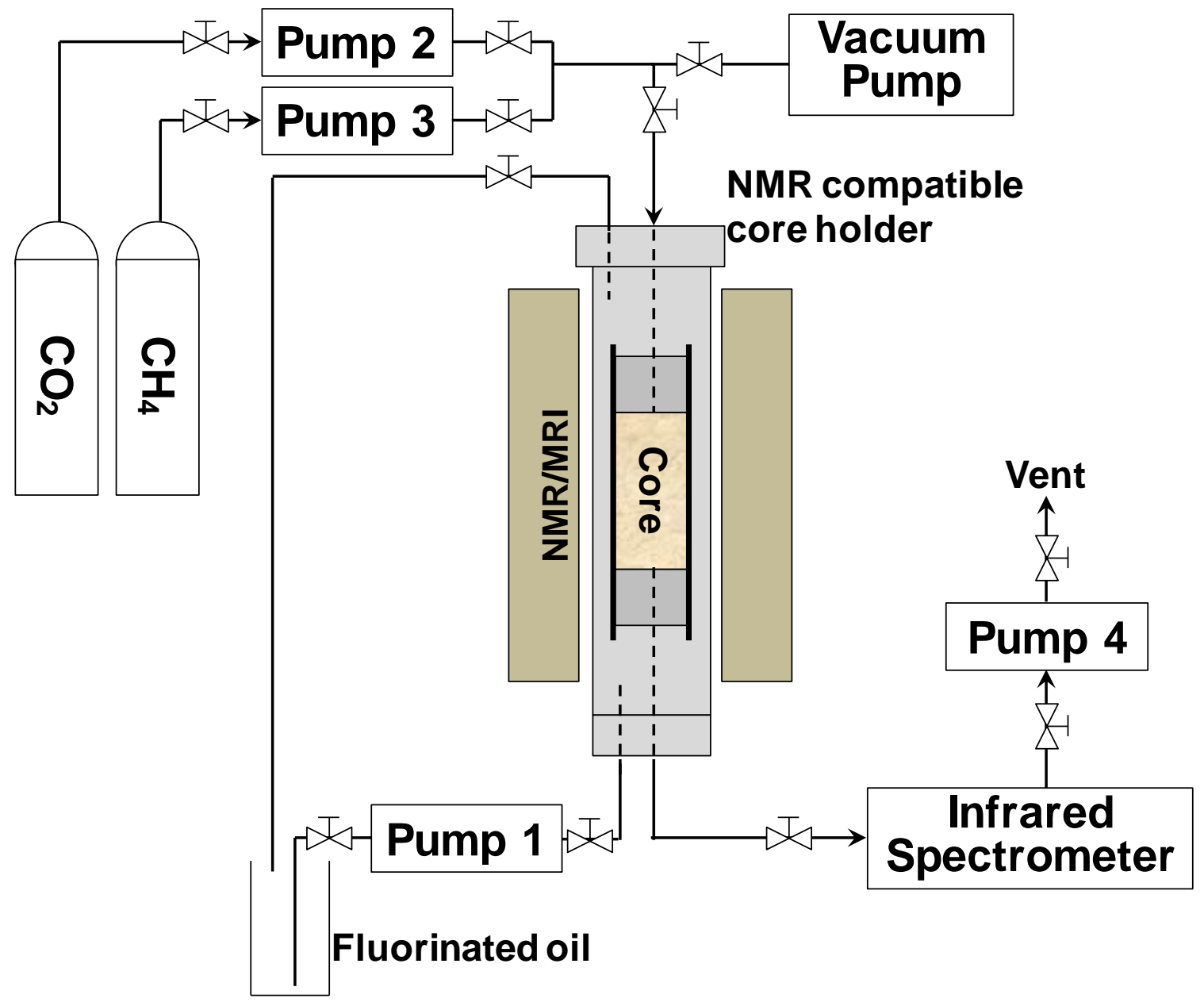

Figure 1 Schematic of experimental apparatus employed for $\mathrm{CH}_{4}$ flooding to displace $\mathrm{CO}_{2}$

497 in the rock sample ('top' to 'bottom' direction). For $\mathrm{CO}_{2}$ flooding to displace $\mathrm{CH}_{4}$, a 498 'bottom' to 'top' direction was employed and the relative positions of core holder inlet and 499 outlet were reversed.

500

501 
(a)

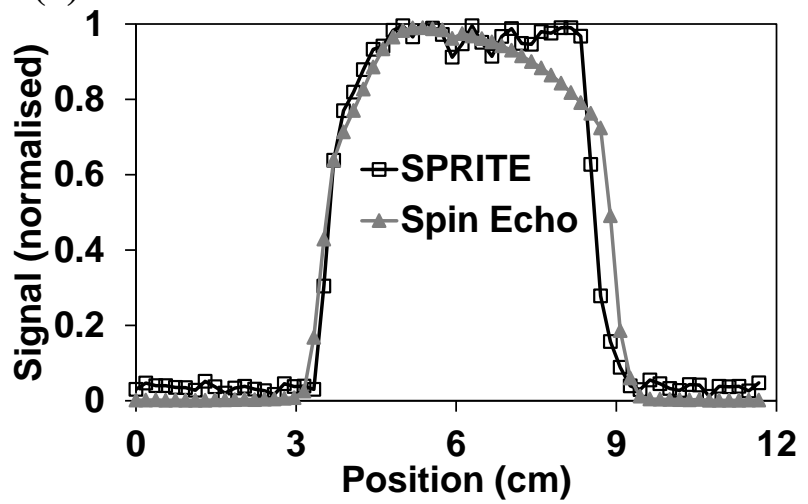

(b)

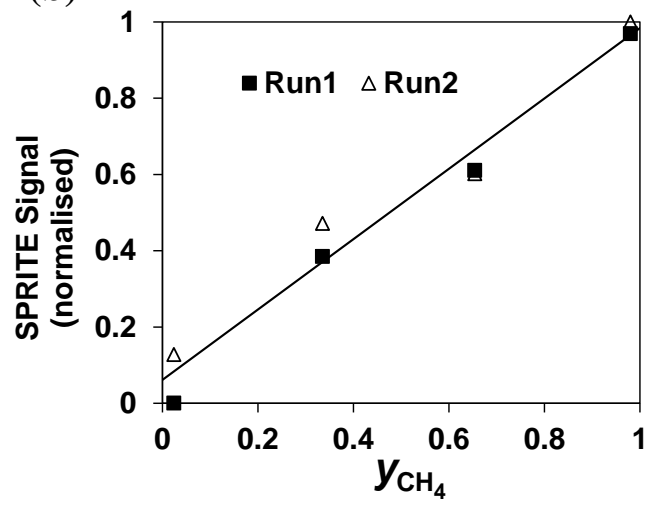

506 Figure 2 (a) 1D MRI profiles of a bottle of water from spin-echo and SPRITE 507 measurements respectively. SPRITE provides a more homogeneous profile than the spin 508 echo to show the expected geometry of the water bottle. The convex profile shape at about $5094 \mathrm{~cm}$ is due to the geometry of the bottle neck. (b) SPRITE MRI signal intensity correlates 510 well with the mole fraction of $\mathrm{CH}_{4}\left(y_{\mathrm{CH}_{4}}\right)$ in various mixtures of $\mathrm{CH}_{4}$ and $\mathrm{CO}_{2}$ in a Berea 511 rock core plug. 


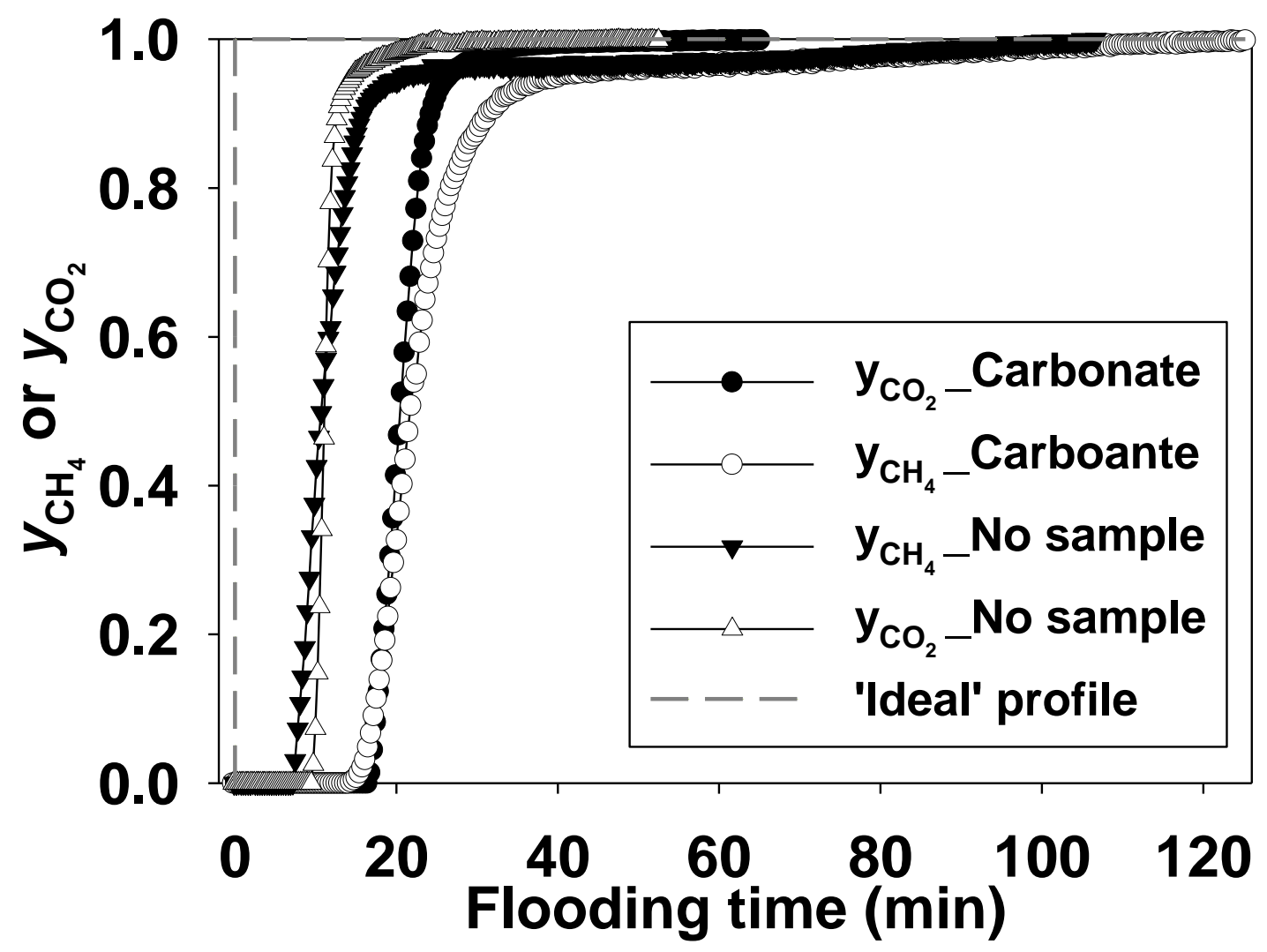

520 Figure 3 Breakthrough curves during $\mathrm{CO}_{2}$ flooding to displace $\mathrm{CH}_{4}\left(y_{\mathrm{CO}_{2}}\right)$ and during $\mathrm{CH}_{4}$

521 flooding to displace $\mathrm{CO}_{2}\left(y_{\mathrm{CH}_{4}}\right)$ with a carbonate core plug and without a core sample, as

522 determined by IR measurements. These flooding processes were undertaken at $40{ }^{\circ} \mathrm{C}$ and

523100 bar with a flooding rate of $2 \mathrm{ml} / \mathrm{min}$. The solid lines are added to guide the eye. The 524 gray dashed line represents an 'ideal' situation for reference, corresponding to the 525 concentration of the displacing gas phase instantly increased from 0 to 1 . 
(a) Berea sandstone

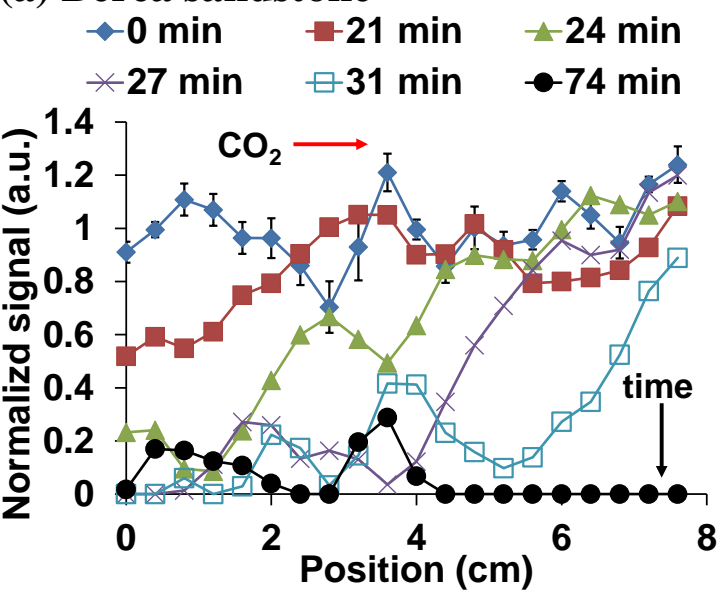

(c) Carbonate

$\neg 0$ min

$$
\rightarrow-17 \mathrm{~min} \quad-21 \mathrm{~min}
$$

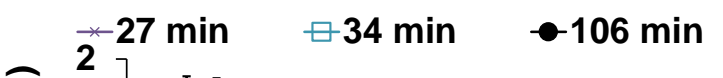

529

\section{0}

531

532

533

534

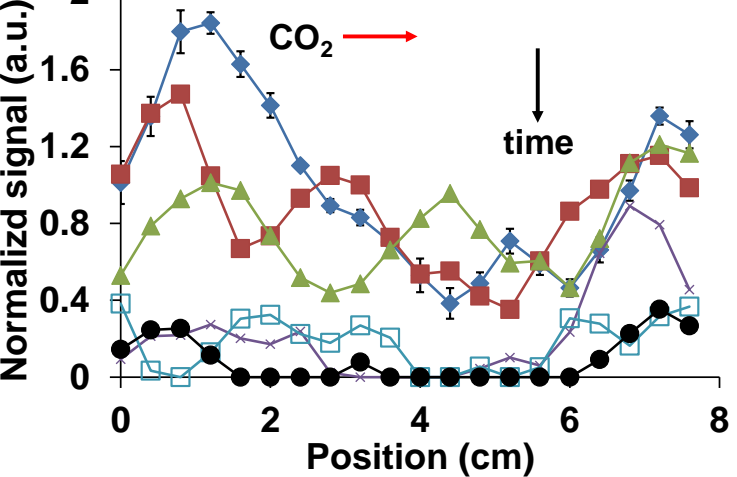

(b) Berea sandstone

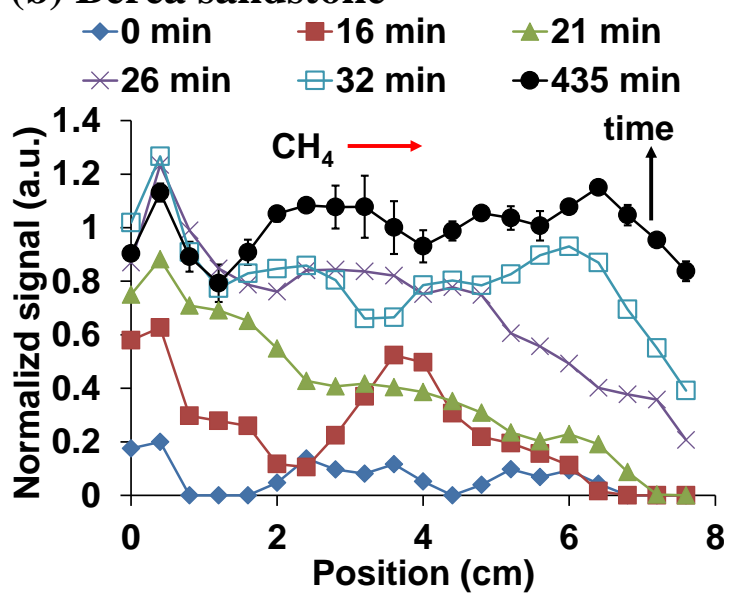

(d) Carbonate

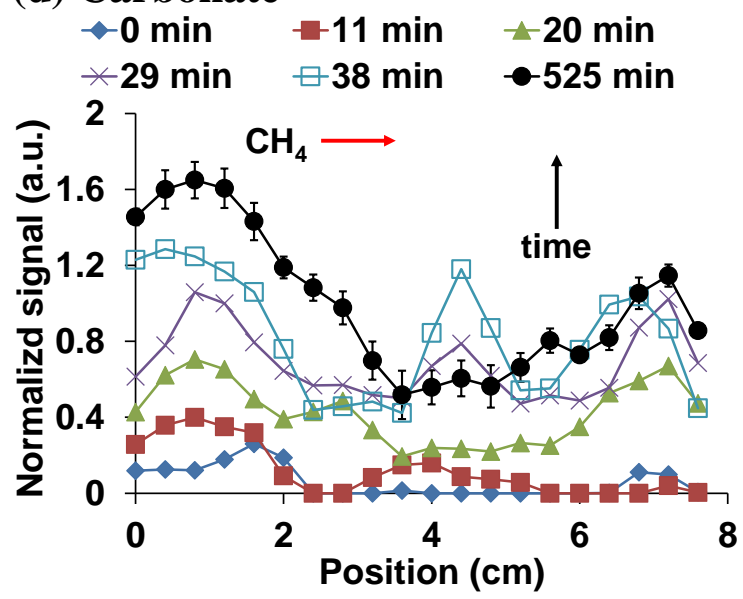

Figure 4 Sample 1D $\mathrm{CH}_{4}$ distribution profiles along the Berea sandstone $(\mathrm{a}, \mathrm{b})$ and carbonate (c, d) core plugs during $\mathrm{CO}_{2}$ flooding to displace $\mathrm{CH}_{4}(\mathrm{a}, \mathrm{c})$ and $\mathrm{CH}_{4}$ flooding to displace $\mathrm{CO}_{2}$ (b, d). A value of 1 corresponds to the mean $\mathrm{CH}_{4}$ signal for the whole rock core when it contained only $\mathrm{CH}_{4}$. All the core flooding processes were undertaken at 100 bar and $20{ }^{\circ} \mathrm{C}$ with a volume flooding rate of $0.5 \mathrm{ml} / \mathrm{min}$. Red arrows indicate the flooding directions and black arrows the time sequence of the profiles. 
(a)

(b)
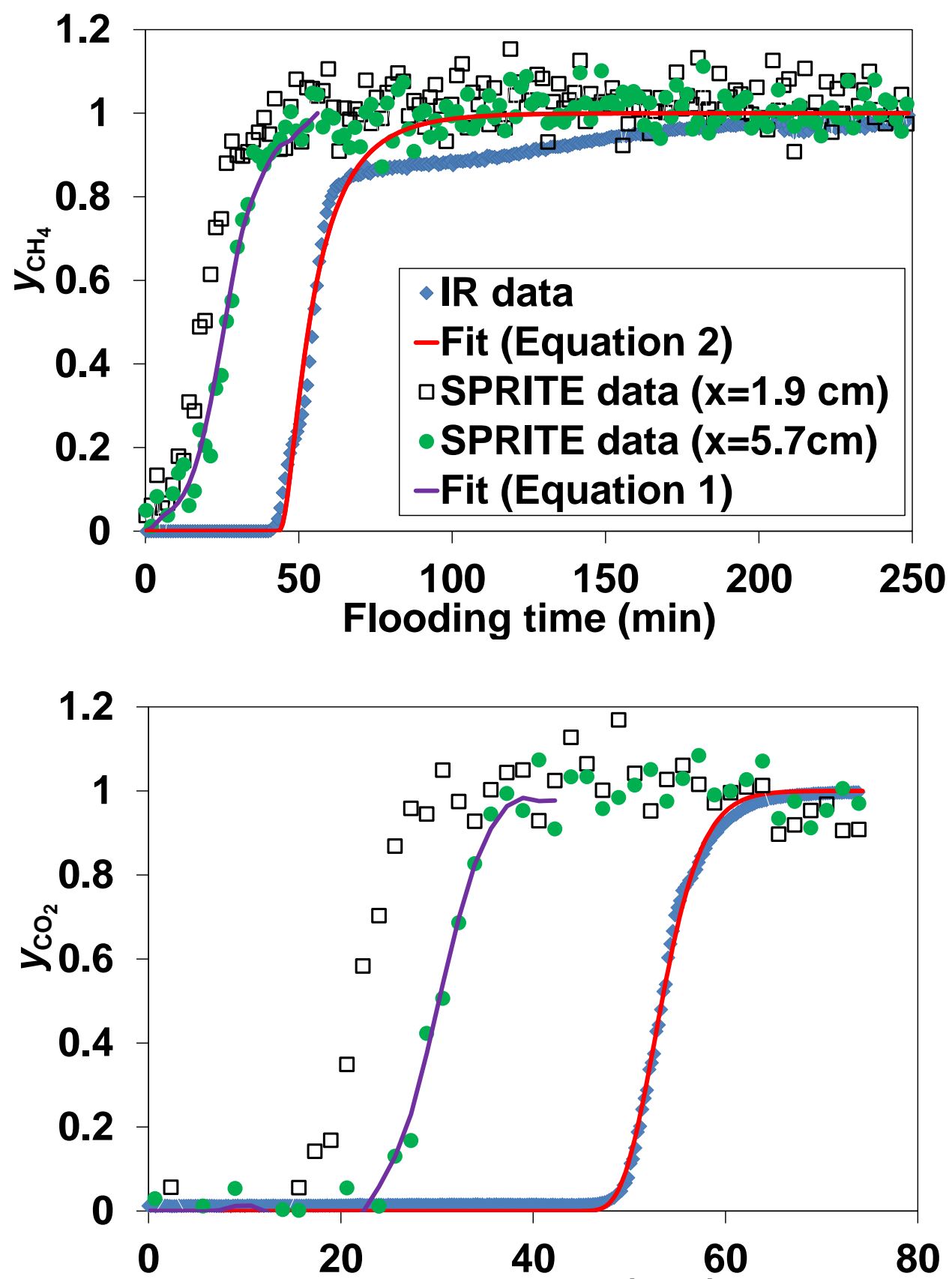

Flooding time (min)

546 the Berea core plug. (a) $\mathrm{CH}_{4}$ flooding to displace $\mathrm{CO}_{2}$ and (b) $\mathrm{CO}_{2}$ flooding to displace $547 \mathrm{CH}_{4}$. All flooding processes were undertaken at $20{ }^{\circ} \mathrm{C}$ and 100 bar with a flooding rate of $5480.0829 \mathrm{~mm} / \mathrm{s}$. The fits of Equations (1) and (2) to the MRI and IR data, respectively, are 549 also shown. 
$551 \quad$ (a)

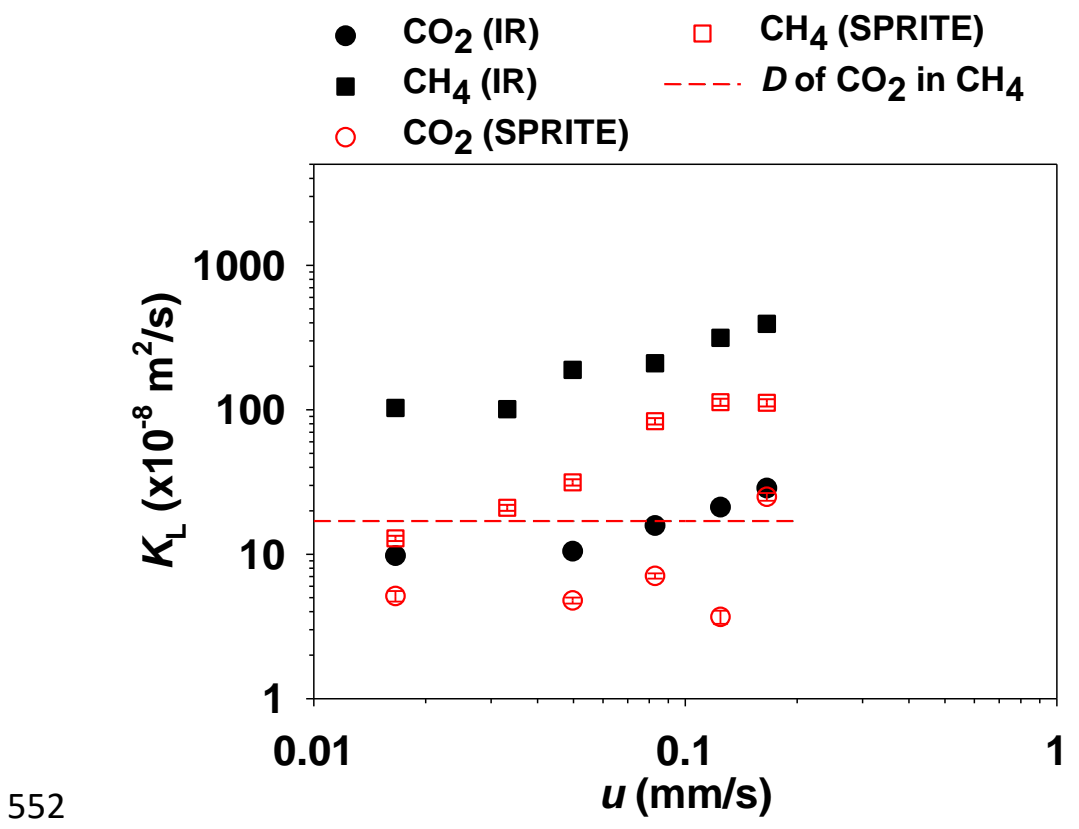

553 (b)

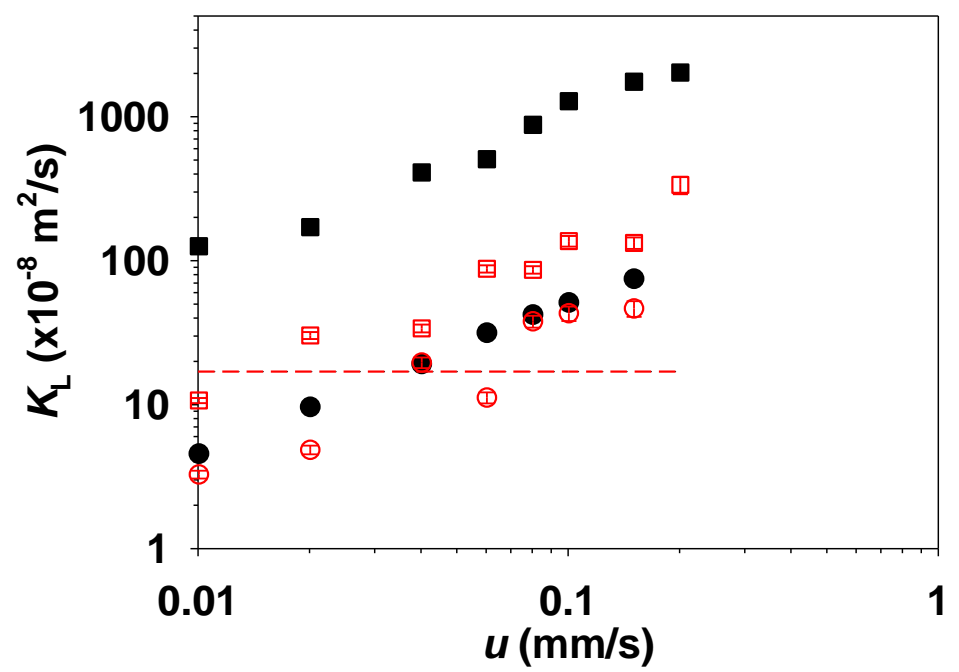

555 Figure 6 Gas dispersion coefficients $\left(K_{\mathrm{L}}\right)$ as determined from IR and MRI measurements 556 for (a) Berea and (b) carbonate core plugs. The diffusion coefficient (D) of $\mathrm{CO}_{2}$ in $\mathrm{CH}_{4}$ is $5571.7 \times 10^{-7} \mathrm{~m}^{2} / \mathrm{s}$ and is shown by the dashed red line. 


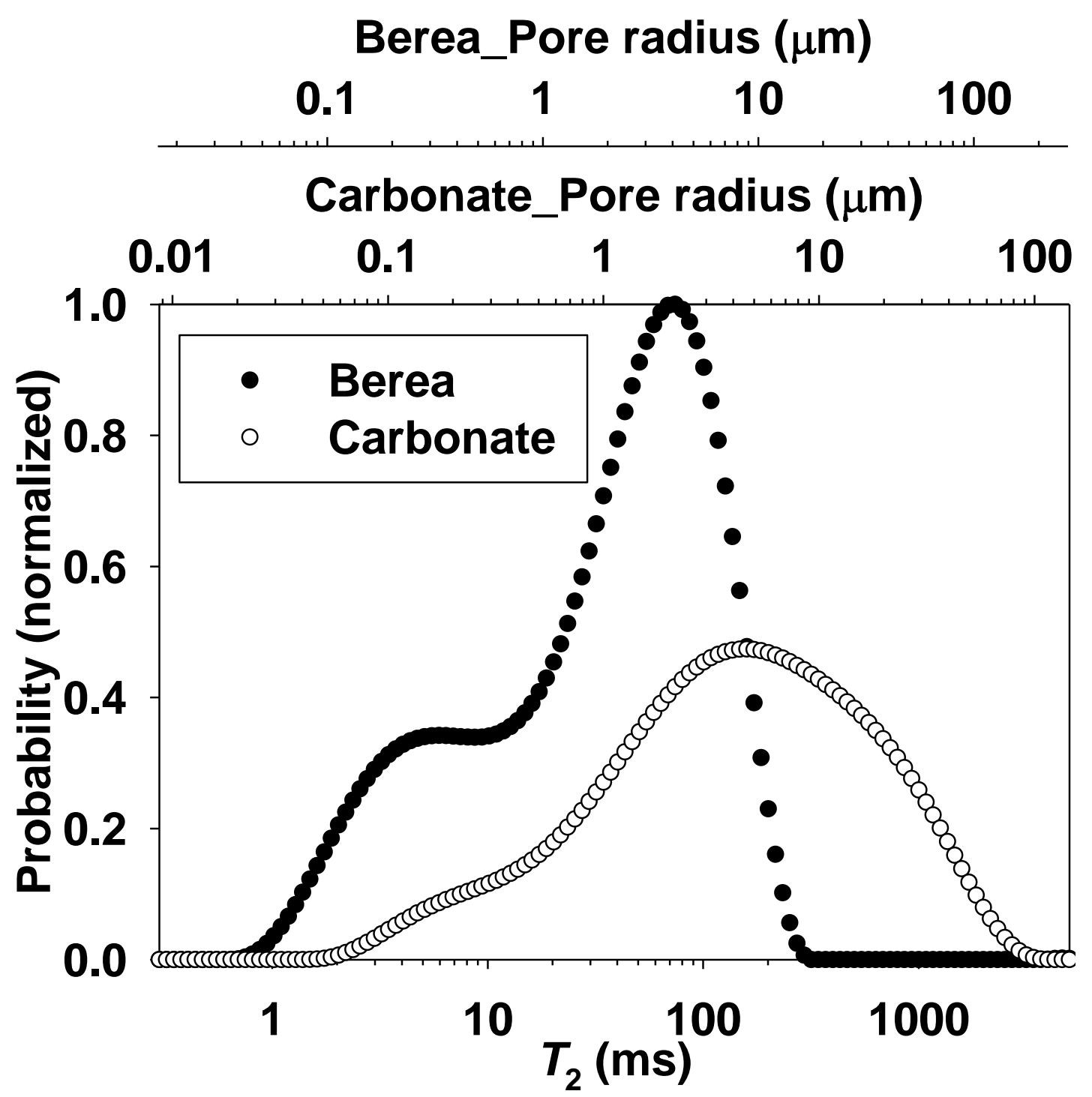

562 Figure $7 T_{2}$ distribution of Berea and carbonate rock core plugs, fully saturated with

563 brine solution $(1 \mathrm{wt} \% \mathrm{NaCl})$. The pore size distribution is also presented as determined

564 using Equation (5) with relaxivity values of $18.2 \mu \mathrm{m} / \mathrm{s}$ and $9.6 \mu \mathrm{m} / \mathrm{s}$ for the Berea and

565 carbonate core plugs, respectively.

566

567

568

569

570 
(a)

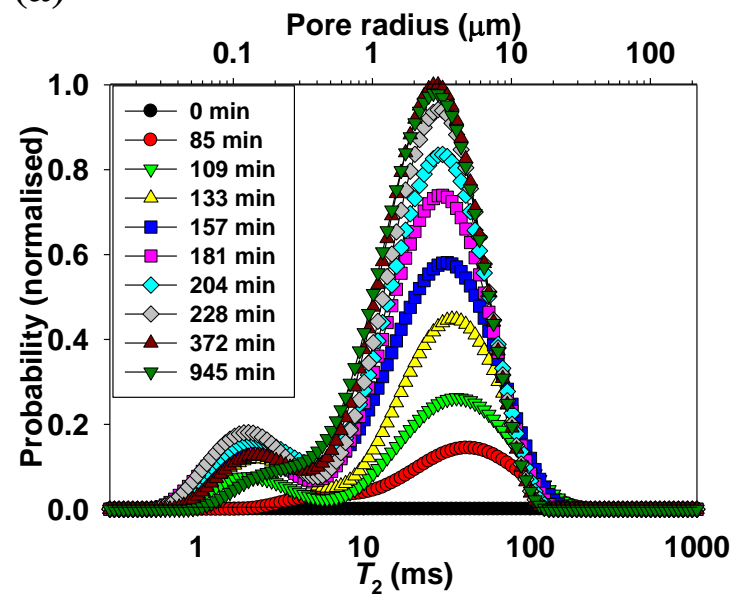

(c)

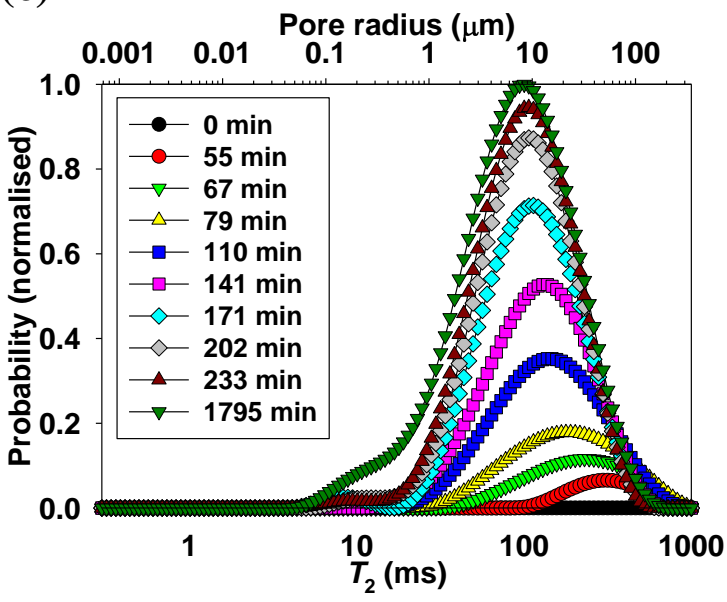

(b)

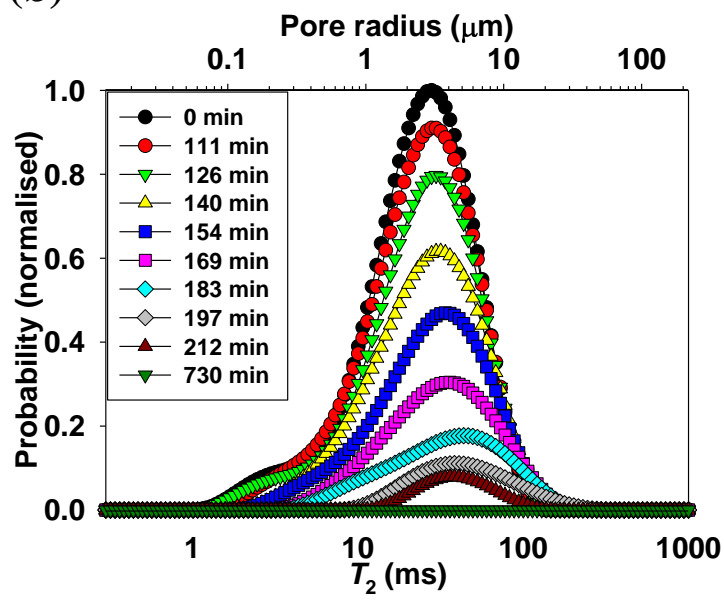

(d)

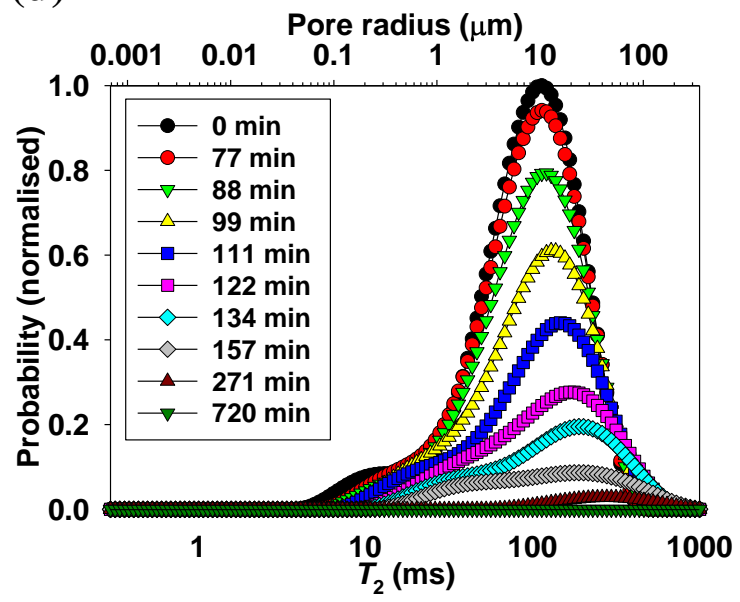

Figure 8 Pore size distribution and $T_{2}$ relaxation time distribution of $\mathrm{CH}_{4}$ in Berea $(\mathrm{a}, \mathrm{b})$

573 and carbonate core plugs (c, d) during $\mathrm{CH}_{4}$ flooding to displace $\mathrm{CO}_{2}(\mathrm{a}, \mathrm{c})$ and during $\mathrm{CO}_{2}$

574 flooding to displace $\mathrm{CH}_{4}(\mathrm{~b}, \mathrm{~d})$. 
(a)

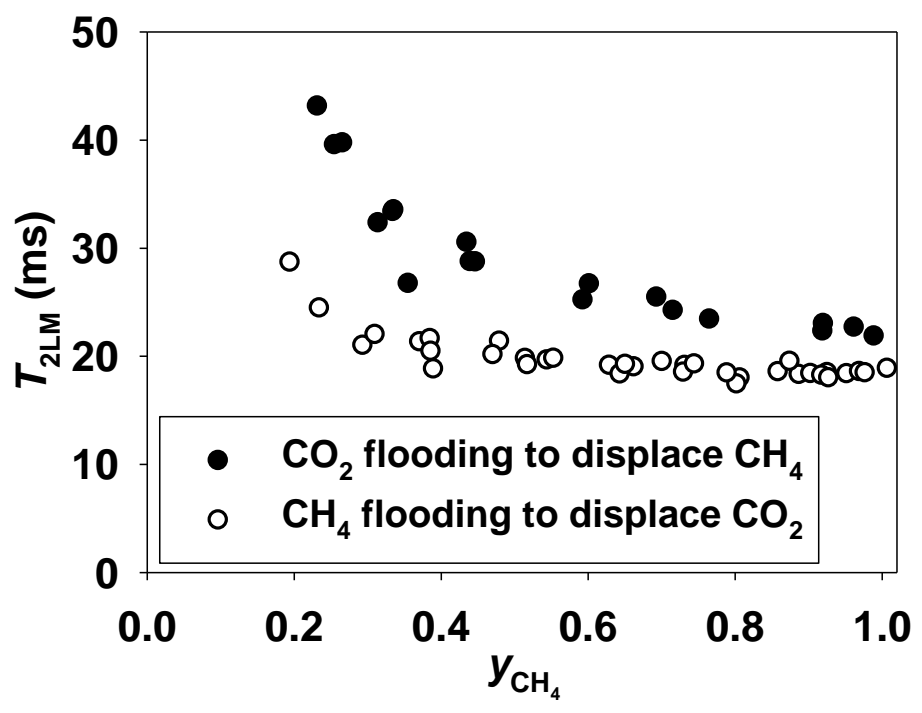

(b)

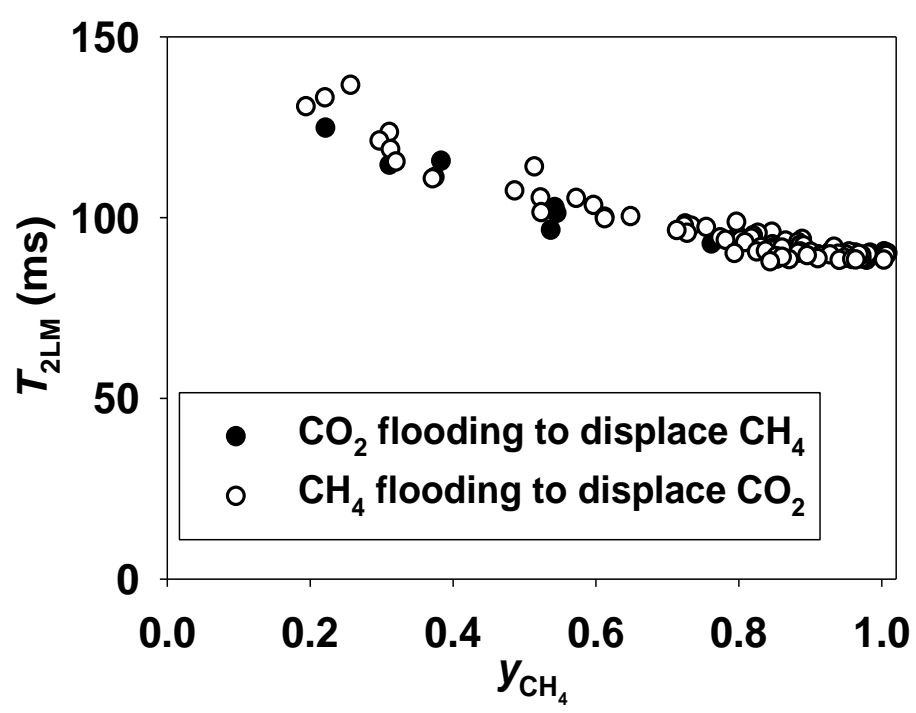

576 Figure $9 T_{2} \log$ mean $\left(T_{2 \mathrm{LM}}\right)$ of $\mathrm{CH}_{4}$ in (a) Berea and (b) carbonate core plugs plotted as a 577 function of $\mathrm{CH}_{4}$ mole fraction $\left(y_{\mathrm{CH}_{4}}\right) . T_{2 \mathrm{LM}}$ and $y_{\mathrm{CH}_{4}}$ are determined from the bulk CPMG 578 measurement and the mean of SPRITE signal along the $\mathrm{CH}_{4}$ profile, respectively. $T_{2 \mathrm{LM}}$ 579 corresponding to $y_{\mathrm{CH}_{4}}<0.19$ are not shown due to low SNR. 


\section{References}

583 Akkurt, R., Vinegar, H.J., Tutunjian, P.N., Guillory, A.J.: NMR logging of natural gas reservoirs. The Log Analyst 37(6), 33-42 (1996).

Balcom, B.J., MacGregor, R.P., Beyea, S.D., Green, D.P., Armstrong, R.L., Bremner, T.W.: Single point ramped imaging with $T_{1}$ enhancement (SPRITE). J. Magn. Reson., Ser. A 123(1), 131-134 (1996). https://doi.org/10.1006/jmra.1996.0225

Barrufet, M.A., Bacquet, A., and Falcone, G.: Analysis of the storage capacity for $\mathrm{CO}_{2}$ sequestration of a depleted gas condensate reservoir and a saline aquifer. J. Can. Pet. Technol. 49(8), 23-31 (2010). http://dx.doi.org/10.2118/139771-PA

Blackwell, R.J.: Laboratory studies of microscopic dispersion phenomena. Soc. Pet. Eng. J. 2, 1-8 (1962). https://doi.org/10.2118/1483-G

Blok, K., Williams, R.H., Katofsky, R.E., Hendriks, C.A.: Hydrogen production from natural gas, sequestration of recovered $\mathrm{CO}_{2}$ in depleted gas wells and enhanced natural gas recovery. Energy 22, 161-168 (1997). https://doi.org/10.1016/S03605442(96)00136-3

Brigham, W.E., Reed, P.W., Dew, J.N.: Experiments on mixing during miscible displacement in porous media. Soc. Pet. Eng. J. 1 (1), 1-8 (1961). https://doi.org/10.2118/1430-G

Carneiro, G., Souza, A., Boyd, A., Schwartz, L., Song, Y., Azeredo, R., Trevizan, W., Santos, B., Rios, E., Machado, V. Evaluating pore space connectivity by NMR diffusive coupling. Presented at the SPWLA 55 ${ }^{\text {th }}$ Annual Logging Symposium, Abu Dhabi, 18-22 May 2014.

Chang, D., Vinegar, H, Morriss, C., Straley, C.: Effective porosity, producible fluid and permeability in carbonates from NMR logging. Presented at the SPWLA $35^{\text {th }}$ Annual Logging Symposium, Tulsa, Oklahoma, 19-22 June 1994.

Cheng, Y., Huang, Q., Eic, M., Balcom, B.J.: $\mathrm{CO}_{2}$ dynamic adsorption/desorption on zeolite 5A studied by ${ }^{13} \mathrm{C}$ magnetic resonance imaging. Langmuir 21(10), 43764381 (2005). doi:10.1021/la047302p

Coates, G.R., Xiao, L., Prammer, M.G.: NMR logging principles and applications. Halliburton Energy Services, Houston, TX, USA (1999).

Connolly, P.R.J., Vogt, S.J., Iglauer, S., May, E.F., Johns, M.L.: Capillary trapping quantification in sandstones using NMR relaxometry. Wat. Resources Res. 53 (9) 7917-7932 (2017). https://doi.org/10.1002/2017WR020829 
Connolly, P.R.J., Yan, W., Zhang, D., Mahmoud, M., Verrall, M., Lebedev, M., Iglauer, S., Metaxas, P., May, E.F., Johns, M.L. Simulation and experimental measurements of internal magnetic field gradients and NMR transverse relaxation times $\left(T_{2}\right)$ in sandstone rocks. J. Pet. Sci. Eng. 175, 985-997 (2019). https://doi.org/10.1016/j.petrol.2019.01.036

Delgado, J. M. P. Q.: Longitudinal and transverse dispersion in porous media. Chem. Eng. Res. Des. 85 (9), 1245-1252 (2007). https://doi.org/10.1205/cherd07017

Edwards, M.F., Richardson, J.F.: Gas dispersion in packed beds. Chem. Eng. Sci. 23(2), 109-123 (1968). https://doi.org/10.1016/0009-2509(68)87056-3

Ehrenberg, S.N., Nadeau, P.H.: Sandstone vs. carbonate petroleum reservoirs: A global perspective on porosity-depth and porosity-permeability relationships. AAPG Bulletin 89(4), 435-445 (2005). https://doi.org/10.1306/11230404071

Freedman, R., Heaton, N., Flaum, M., Hirasaki, G.J., Flaum, C., Hürlimann, M. Wettability, saturation, and viscosity from NMR measurements. SPE J. 8(4), 317327 (2003). https://doi.org/10.2118/87340-PA

Guntuka, S., Farooq, S., Rajendran, A.: A- and B-site substituted lanthanum cobaltite perovskite as high temperature oxygen sorbent. 2. Column dynamics study. Ind. Eng. Chem. Res. 47(1), 163-170 (2008). doi:10.1021/ie070860p

Honari, A., Bijeljic, B., Johns, M. L., May, E. F.: Enhanced gas recovery with $\mathrm{CO}_{2}$ sequestration: The effect of medium heterogeneity on the dispersion of supercritical $\mathrm{CO}_{2}-\mathrm{CH}_{4}$. Int. J. Greenh. Gas Control 39, 39-50 (2015a). https://doi.org/10.1016/j.ijggc.2015.04.014

Honari, A., Vogt, S.J., May, E.F., Johns, M.L.: Gas-gas dispersion coefficient measurements using low-field MRI. Transp. Porous Med. 106, 21-32 (2015b). https://doi.org/10.1007/s11242-014-0388-2

Honari, A., Zecca. M., Vogt, S.J., Iglauer, S., Bijeljic, B., Johns, M.L., May, E.F.: The impact of residual water on $\mathrm{CH}_{4}-\mathrm{CO}_{2}$ dispersion in consolidated rock cores. Int. J. Greenh. Gas Control 50, 100-111 (2016). https://doi.org/10.1016/j.ijggc.2016.04.004

Hughes, T.J., Honari, A., Graham, B.F., Chauhan, A.S., Johns, M.L., May, E.F.: $\mathrm{CO}_{2}$ sequestration for enhanced gas recovery: new measurements of supercritical $\mathrm{CO}_{2-}$ $\mathrm{CH}_{4}$ dispersion in porous media and a review of recent research. Int. J. Greenh. Gas Control 9, 457-468 (2012). https://doi.org/10.1016/j.ijggc.2012.05.011 
Johnson, A.C. Investigation of porous media using nuclear magnetic resonance secular relaxation measurements and micro-CT image analysis. MSc thesis, University of Texas at Austin, USA (2015).

Kheshgi, H.S., Thomann, H., Bhore, N.A., Hirsch, R.B., Parker, M.E., Teletzke, G.: Perspectives on CCS Cost and Economics. SPE Econ. Mgmt. 4(1): 24-31 (2012). http://dx.doi.org/10.2118/139716-PA

Leung, D.Y.C., Caramanna, G., Maroto-Valer, M.M.: An overview of current status of carbon dioxide capture and storage technologies. Renew. Sust. Energ. Rev. 39, 426-443 (2014). https://doi.org/10.1016/j.rser.2014.07.093

Laesecke, A., Muzny, C.D.: Reference correlation for the viscosity of carbon dioxide. J. Phys. Chem. Ref. Data 46, 013107 (2017). https://doi.org/10.1063/1.4977429

Lemmon, E.W., Bell, I.H., Huber, M.L., McLinden, M.O.: REFPROP 10.0 (2018) Reference Fluid Thermodynamic and Transport Properties, NIST Standard Reference Database 23, DLL Version 10.0.

Li, M., Romero-Zerón, L., Marica, F., Balcom, B.J.: Polymer flooding enhanced oil recovery evaluated with magnetic resonance imaging and relaxation time measurements. Energy Fuels 31, 4904-4914 (2017a). doi:10.1021/acs.energyfuels.7b00030

Li, M., Vashaee, S., Romero-Zerón, L., Marica, F., Balcom, B.J.: A magnetic resonance study of low salinity waterflooding for enhanced oil recovery. Energy Fuels 31, 10802-10811 (2017b). doi:10.1021/acs.energyfuels.7b02166

Li, M., Xiao, D., Romero-Zerón, L., Marica, F., MacMillan, B., Balcom, B. J.: Mapping three-dimensional oil distribution with $\pi$-EPI MRI measurements at low magnetic field. J. Magn. Reson. 269, 13-23 (2016). https://doi.org/10.1016/j.jmr.2016.05.008

Mesquita, P., Souza, A., Carneiro, G., Boyd, A., Ferreira, F., Machado, P., Anand, V.: Surface relaxivity estimation and NMR-MICP matching in diffusionaly coupled rocks. Presented at the International Symposium of the Society of Core Analysts, Snowmass, Colorado, 21-26 August 2016; paper SCA2016-059.

Lucia, F.J., Kerans, C., Jennings, J.W.: Carbonate reservoir characterization. Soc. Pet. Eng. 55(6), 70-72 (2003). https://doi.org/10.2118/82071-JPT

Mitchell, J., Chandrasekera, T.C., Holland, D.J., Gladden, L.F., Fordham, E.J.: Magnetic resonance imaging in laboratory petrophysical core analysis. Phys. Rep. 526(3), 165-225 (2013). https://doi.org/10.1016/j.physrep.2013.01.003 
Mitchell, J., Chandrasekera, T.C, Johns, M.L., Gladden, L.F.: Nuclear magnetic resonance relaxation and diffusion in the presence of internal gradients. Phys. Rev. E 81, 026101 (2010). https://doi.org/10.1103/PhysRevE.81.026101

Mitchell, J., Fordham, E.J.: Solium-23 NMR in porous media. Microporous Mesoporous Mater. 269, 109-112 (2018). https://doi.org/10.1016/j.micromeso.2017.02.004

Muir, C.E., Balcom, B.J.: Pure phase encode magnetic resonance imaging of fluids in porous media. Annu. Rep. NMR Spectrosc. 77, 81-113 (2012). https://doi.org/10.1016/B978-0-12-397020-6.00002-7

Newling, B.: Gas flow measurements by NMR. Prog. Nucl. Magn. Reson. Spectrosc. 52(1), 31-48 (2008). https://doi.org/10.1016/j.pnmrs.2007.08.002

Oldenburg, C.M., Benson, S.M.: $\mathrm{CO}_{2}$ injection for enhanced gas production and carbon sequestration. Presented at the SPE International Petroleum Conference and Exhibition, Villahermosa, Mexico, 10-12 February 2002; paper SPE 74367.

Patel, M.J., May, E.F., Johns, M.L.: High-fidelity reservoir simulations of enhanced gas recovery with supercritical $\mathrm{CO}_{2}$. Energy 111, 548-559 (2016). https://doi.org/10.1016/j.energy.2016.04.120

Patel, M.J., May, E.F., Johns, M.L.: Inclusion of connate water in enhanced gas recovery reservoir simulations. Energy 141, 757-769 (2017). https://doi.org/10.1016/j.energy.2017.09.074

Pooladi-Darvish, M., Hong, H., Theys, S., Stocker, R., Bachu, S., Dashtgard, S.: $\mathrm{CO}_{2}$ injection for enhanced gas recovery and geological storage of $\mathrm{CO}_{2}$ in the Long Coulee Glauconite F Pool, Alberta. Presented at the SPE Annual Technical Conference and Exhibition, Denver, Colorado, 21-24 September 2008; Paper SPE 115789.

Rajendran, A., Kariwala, V., Farooq, S.: Correction procedures for extra-column effects in dynamic column breakthrough experiments. Chem. Eng. Sci. 63(10), 26962706 (2008). https://doi.org/10.1016/j.ces.2008.02.023

Ramskill, N.P., Sederman, A.J., Mantle, M.D., Appel, M., de Jong, H., Gladden, L.F.: In Situ Chemically-Selective Monitoring of Multiphase Displacement Processes in a Carbonate Rock Using 3D Magnetic Resonance Imaging. Transp. Porous Med. 121(1), 15-35 (2018). https://doi.org/10.1007/s11242-017-0945-6

Seo, J.G., Mamora, D.D.: Experimental and simulation studies of sequestration of supercritical carbon dioxide in depleted gas reservoirs. J. Energy Resour. Technol. 127(1), 1-6 (2005). https://doi.org/10.2118/81200-MS 
Shikhov, I, Li, R, Arns C.H.: Relaxation and relaxation exchange NMR to characterise asphaltene adsorption and wettability dynamics in siliceous systems. Fuel 220, 692-705 (2018). http://dx.doi.org/10.1016/j.fuel.2018.02.059

Shikhov, I, Arns C.H.: Tortuosity estimate through paramagnetic gas diffusion in rock saturated with two fluids using $T_{2}(\mathrm{z}, \mathrm{t})$ low-field NMR. Diffusion Fundamentals 29, 1-7 (2017).

Takahashi, S., Iwasaki, H.: The diffusion of gases at high pressures. III. The diffusion of ${ }^{14} \mathrm{CO} 2$, in the ${ }^{12} \mathrm{CO}_{2}-\mathrm{CH}_{4}$ system. Bulletin of the Chemical Research Institute of Non-Aqueous Solutions, Tohoku University 20, 27-36 (1970).

Takahashi S.: The diffusion of gases at high pressures. IV. The diffusion of $\mathrm{CTH}_{3}$ in the $\mathrm{CH}_{4}-\mathrm{CO}_{2}$ system. Bull. Chem. Soc. Jpn. 45, 2074-2078 (1972). https://doi.org/10.1246/bcsj.45.2074

Taylor, G.: Dispersion of soluble matter in solvent flowing slowly through a tube. Proc. R. Soc. Lond. Ser. A 219(1137), 186-203 (1953). doi:10.1098/rspa.1953.0139

Taylor, G.: Conditions under which dispersion of a solute in a stream of solvent can be used to measure molecular diffusion. Proc. R. Soc. Lond. Ser. A 225(1163), 473477 (1954). doi:10.1098/rspa.1954.0216

Timur, A.: Nuclear magnetic resonance study of carbonate rocks. The Log Analyst 13(5), 3-11 (1972).

Vashaee, S, Newling, B., MacMillan, B., Balcom, B.J. $B_{1}$ mapping with a pure phase encode approach: Quantitative density profiling. J. Magn. Reson. 232, 68-75 (2013). http://dx.doi.org/10.1016/j.jmr.2013.04.012

Xia, M.: Pore-scale simulation of miscible displacement in porous media using the lattice Boltzmann method. Comput. Geosci. 88, 30-40, (2016). https://doi.org/10.1016/j.cageo.2015.12.014

Xiao, D., Balcom, B.J. $k$-t acceleration in pure phase encode MRI to monitor dynamic flooding processes in rock core plugs. J. Magn. Reson. 243, 114-121 (2014). https://doi.org/10.1016/j.jmr.2014.04.006

Yu, D., Jackson, K., Harmon, T.C.: Dispersion and diffusion in porous media under supercritical conditions. Chem. Eng. Sci. 54(3), 357-367 (1999). https://doi.org/10.1016/S0009-2509(98)00271-1

Zecca, M., Vogt, S.J., Connolly, P.R., May, E.F., Johns, M.L.: NMR measurements of tortuosity in partially saturated porous media. Transp. Porous Med. 125(2), 271288 (2018). https://doi.org/10.1007/s11242-018-1118-y 
750 Zecca, M., Vogt, S.J., Honari, A., Xiao, G., Fridjonsson, E.O., May, E.F., Johns, M.L.:

751 Quantitative dependence of $\mathrm{CH}_{4}-\mathrm{CO}_{2}$ dispersion on immobile water fraction.

$752 \quad$ AIChE J 63 (11), 5159-5168 (2017). https://doi.org/10.1002/aic.15824

753 Zhang, Y., Liu, S., Wang, L., Song, Y., Yang, M., Zhao, J., Zhao, Y., Chi, Y. In situ

754 measurement of the dispersion coefficient of liquid/supercritical $\mathrm{CO}_{2}-\mathrm{CH}_{4}$ in a

755 sandpack using CT. RSC Adv. 6, 42367-42376 (2016).

756 DOI:10.1039/C6RA00763E

757 Zhao, Y., Song, Y.: Experimental investigation on spontaneous counter-current

758 imbibition in water-wet natural reservoir sandstone core using MRI. Magn.

759 Reson. Chem. 55(6), 546-552 (2016). https://doi.org/10.1002/mrc.4563 